\title{
Citizen-Oriented Digital Transformation in the Public Sector
}

\author{
Prof. Dr. Ines Mergel \\ University of Konstanz \\ Konstansz, Germany \\ ines.mergel@uni-konstanz.de \\ Dr. Veiko Lember \\ Public Governance Institute, KU Leuven \\ Leuven, Belgium \\ veiko.lember@kuleuven.be
}

\author{
Prof. Dr. Rainer Kattel \\ Institute of Innovation and Public Purpose, UCL \\ London, United Kingdom \\ r.kattel@ucl.ac.uk \\ Keegan McBride, MSc \\ Tallinn University of Technology \\ Tallinn, Estonia \\ keegan.mcbride@ttu.ee
}

\begin{abstract}
Digital transformation has emerged as a term that describes the departure from digitization efforts to a full stack revision of the policies, processes and services in order to create simpler user experiences for citizens and frontline workers. While previous waves of digitization focused on the transition from analog to (parallel) digital services to increase efficiency and effectiveness of government services, digital transformation aims to redesign and reengineer government services from the ground up to fulfill changing user needs. At the center of these efforts are users - both internal and external users - of digital services who are included in the digital transformation efforts. This panel therefore brings together four aspects of digital transformation: a) dynamic capabilities as a precondition for digital transformation; b) co-design of digital services with users; c) digital co-production and co-creation to increase legitimacy of digital services; and d) co-creation with open data to improve digital service delivery.
\end{abstract}

\section{CCS CONCEPTS}

- Applied computing $\rightarrow$ E-government;

\section{KEYWORDS}

Digital Transformation, Co-Creation, Public Services

\section{ACM Reference Format:}

Prof. Dr. Ines Mergel, Prof. Dr. Rainer Kattel, Dr. Veiko Lember, and Keegan McBride, MSc. 2018. Citizen-Oriented Digital Transformation in the Public Sector. In Proceedings of 19th Annual International Conference on Digital Government Research (dg.o'18), Anneke Zuiderwijk and Charles C. Hinnant (Eds.). ACM, New York, NY, USA, Article 4, 3 pages.

\section{PANEL FORMAT 1.5 HOURS}

- Short presentations by invited speakers, 15 minutes per speaker.

- Followed by audience Q\&A.

Permission to make digital or hard copies of part or all of this work for personal or classroom use is granted without fee provided that copies are not made or distributed for profit or commercial advantage and that copies bear this notice and the full citation on the first page. Copyrights for third-party components of this work must be honored.

For all other uses, contact the owner/author(s).

dg.o'18, fune 2018, Delft, $N l$

(c) 2018 Copyright held by the owner/author(s)

\section{MODERATOR}

Dr. Erkki Karo is the Director and Senior Researcher at Ragnar Nurkse Department of Innovation and Governance, Tallinn University of Technology, Estonia. His research focuses on governance and management of innovation systems and policies with focus on state policy and administrative capacities necessary for technological innovations. He is a co-chair of the permanent study group on Public Administration, Technology \& Innovation at the European Group for Public Administration.

\section{PANELISTS AND ISSUES ADDRESSED}

\subsection{Dynamic Capabilities in the Public Sector: The Case of Digital Transformation}

Panelist: Dr. Rainer Kattel is Professor of Innovation and Public Governance at the Institute of Innovation and Public Purpose, UCL. His main research interest include innovation bureaucracy and digital transformations.

While there is a venerable research tradition discussing dynamic capabilities in the private sector there is nothing comparable in the case of the public sector (see, e.g., [1-3]). At the same time, there are ample of examples of public organisations and sometimes whole countries behaving dynamically, that is creating change that significantly alters what government does (see, e.g., [4-6]). Digital transformation offers a good case to study how such capabilities are formed and maintained in the public sector as many countries are attempting to use digital technologies to rethink public organisations and services [7]. This article argues that there are two ideal-typical models of digital transformation - Estonia's country-as-a-service and UK's country-as-a-platform approaches, respectively - that can be studied as different yet parallel cases of not just digital transformation but also of how dynamic capabilities are created and maintained in the public sector. The article is based on interviews with key actors in Estonia and the UK, and traces history and evolution of both concepts (country-as-a-service and country-as-a-platform) and their context specific implementation processes, and successes and failures. This comparison allows to tease out some of the key aspects of dynamic capabilities in the public sector. 


\subsection{Co-designing Digital Services with Users}

Panelist: Dr. Ines Mergel is Professor of Public Administration at the University of Konstanz, Germany. Her research interest focuses on digital transformation and public sector innovations in the public sector.

At the center of digital transformation efforts is the paradigm shift from designing and delivering public services solely based on the internal - policy-driven logic of public administrations to an external, open and co-productive logic of co-designing public services. Previous efforts have left public administrations with problems of non-adoption or even rejection of public services, so that citizens opted to use analog services instead of online services. While these digitization efforts were intended to contribute to time and resource savings, they are oftentimes a replication of existing offline processes, without rethinking mission support or redesign of services, so that citizens are willing to accept them as a reliable alternative to meeting frontline workers in their physical offices. Alternatively, new forms of agility and responsiveness in service delivery are emerging that focus on approaches to co-design and co-produce together with the public [8]. Digital transformation is the next wave of digital governance that introduces the full stack of review and revisions of existing services, instead of simply digitizing analog services. At the center of these forms of co-creation [9] are human-centered design approaches that focus on the inclusion on user needs into the service design process in order to deliver public value [10]. In the public sector, these co-design approaches are currently implemented as part of the work that digital service teams are delivering $[7,11]$. In co-design processes, user needs are extracted with the help of qualitative interviews. Iteratively, a prototype is developed and tested in all phases of the product development cycle that leads to a final service. This paper will discuss the co-design approaches employed by digital services teams and analyze them in order to understand the public value they are contributing to service delivery.

\subsection{Digital Co-Production: New Wine in Old Bottles?}

Panelist: Dr. Veiko Lember is Research Fellow at Public Governance Institute, KU Leuven, Belgium. His main research interests include digital governance, cross-sectoral service delivery and innovation policy.

Co-author: Dr. Piret Tõnurist is a policy analyst for the OECD and a Research Fellow at Ragnar Nurkse Department of Innovation and Governance. Her research topics include innovation policy, energy technologies and social innovation.

Co-author: Dr. Taco Brandsen is Professor of Public Administration, Radboud University, the Netherlands. His research focuses on public services and issues such as innovation, intersection of state, market and civil society, and co-production.

In current digital age, co-production and co-creation have become one the latest buzzwords in the literature dealing with how citizens contribute to public service delivery [12]. There seems to be an emerging consensus that digitization is not only benefiting coproduction by making it more effective and efficient, but it is also fundamentally changing how citizens and service users provide input in public services $[13,14]$. Digital technology can empower individuals and substantially increase opportunities for collective co-production as well as enable more personalized and demanddriven public services. As a result, digital co-production is expected to increase the legitimacy of the state and increase the trust towards the state. At the same time, the conflicting interests and diverging values among stakeholders, the inability of data and algorithms to mirror the complexity of societies, unevenly spread technological capabilities and other factors make digital co-production a fundamentally ambiguous, open-ended and contested process [15]. Moreover, the gradually increasing capabilities of governments to gather, make sense and employ vast amounts of data through social media, sensor networks, data analytics and machine-learning solutions may actually diminish the need for and the role of active citizens in public service (co-)production. At the same time, the empirical evidence demonstrating the expected positive benefits of digital co-production is still scarce at best and rely more on citizen participation in general and inter-organizational collaboration rather than citizen-focused co-production per se [12]. Consequently, the question that emerges and that the contemporary academic debate has so far largely ignored is to what extent (if at all) the emerging digital technologies impact how citizens provide input in co-producing public services? Is digital co-production based on conceptually new premises or is it just the digitization of selected existing (old) co-production practices that we see emerging? For answering these questions, we conceptually unpack the recent trends in digital co-production by analyzing how the stakeholders (who participates in digital co-production and how?), processes (when and in which co-production stage?) and outcomes (which value is created?) are affected by the ongoing digitization in society. Based on selected literature, we categorize the existing case-studies on digital co-production and use these exemplary cases to map the emerging qualities of digital vis-à-vis "traditional" co-production. We aim at providing conceptually better understanding how digitization changes the concept of co-production.

\subsection{Open Government Data-Driven Co-Creation of Public Services}

Panelist: Keegan McBride, MSc is a junior research fellow at Ragnar Nurkse Department of Innovation and Governance at Tallinn University of Technology in Tallinn, Estonia where he is undertaking a PhD under the supervision of Prof. Dr. Robert Krimmer. His primary research interests are open government data, co-creation, machine learning, complexity, and data analytics

An increasing area of interest for e-Government scholars and government practitioners is Open Government Data (OGD). OGD is data that has been collected by a governmental agency and has subsequently been released to the public in such a way that it is accessible, machine readable, human understandable, and redistributable by any party $[16,17]$. Numerous government agencies and public service providers have begun to release and maintain their own OGD programs and portals, but what is often found is that benefits that they expect are not so easily realized [16, 18]. One proposed benefit of OGD that some find to be quite interesting is 
the potential for the creation of new and innovative services that rely upon the exploitation of OGD sources $[16,19]$. It is believed that any interested and technologically able person can create a new service due to the availability of OGD. This benefit of OGD seems to be closely tied to another idea that has been growing in interest by governments and scholars in recent years; co-creation. Co-creation may be understood as "the involvement of outside, non-typical, stakeholders in the initiation, design, implementation, and evaluation of a new public service" [19]. For the purpose of this discussion, it should also be noted that when discussing 'public services' the authors operate using the following definition: public services are "any services which are offered to the general public with the purpose of developing public value, regardless of the role that the public sector plays in the process" [19]. It appears that there may be a bridge between these two concepts. Co-creation represents a change in how users get involved with the creation of new public services, and OGD seems to allow a new way for any stakeholder to create a new public service. If this bridge does indeed exist and the concepts are linked, then the result of OGD-driven co-creation would be a 'co-created OGD-driven public service'. The research at hand aims to use a systems based approach to explore the linkages and relationships between OGD and co-creation. A systems based approach allows for a more holistic understanding to be gained and understand firstly the relationship between OGD and co-creation, but also importantly it is acknowledged that this relationship is highly dependent upon the complex system and environment that it resides in. It is hypothesized that OGD does indeed have the potential to drive the co-creation of new public services, but in order for this to happen it must be allowed to do so. The presence of external environmental factors such as an enabling legal environment, government mindset, motivated stakeholders, innovative leaders, and positive experiences with co-creation or OGD are some potential variables that may allow for OGD-driven co-creation to be enabled.

\section{REFERENCES}

[1] David J. Teece. Dynamic capabilities and entrepreneurial management in large organizations: Toward a theory of the (entrepreneurial) firm. European Economic Review, 86:202-216, jul 2016.

[2] Charles A. O'Reilly and Michael L. Tushman. Ambidexterity as a dynamic capability: Resolving the innovator's dilemma. Research in Organizational Behavior 28:185-206, jan 2008.

[3] Constance E. Helfat and Jeffrey A. Martin. Dynamic Managerial Capabilities. Journal of Management, 41(5):1281-1312, jul 2015.

[4] Fred Block. Swimming Against the Current: The Rise of a Hidden Developmental State in the United States. Politics \& Society, 36(2):169-206, jun 2008.

[5] Dan. Breznitz. Innovation and the state : political choice and strategies for growth in Israel, Taiwan, and Ireland. Yale University Press, 2007.

[6] Mariana Mazzucato. The entrepreneurial state : debunking public vs. private sector myths. Anthem Press, revised edition, 2013.

[7] Ines Mergel. Digital Service Teams : Challenges and Recommendations for Government. 2017.

[8] Ines Mergel. Agile innovation management in government: A research agenda. Government Information Quarterly, 33(3):516-523, 2016.

[9] C.K. Prahalad and Venkat Ramaswamy. Co-creation experiences: The next practice in value creation. Fournal of Interactive Marketing, 18(3):5-14, jan 2004

[10] Elizabeth B.-N. Sanders and Pieter Jan Stappers. Co-creation and the new landscapes of design. CoDesign, 4(1):5-18, mar 2008.

[11] Amanda Clarke. Digital government units: Origins, orthodoxy and critical considerations for public management theory and practice. 2017

[12] Veiko Lember. The role of new technologies in co-production. In T Brandsen, T Steen, and B Verschuere, editors, Co-production and co-creation: engaging citizens in public service delivery., number forthcoming. Routledge, 2018.
[13] Dennis Linders. From e-government to we-government: Defining a typology for citizen coproduction in the age of social media. Government Information Quarterly, 29(4):446-454, 2012.

[14] Beth Simone. Noveck. Smart citizens, smarter state : the technologies of expertise and the future of governing. Harvard University Press, 2015.

[15] Paolo Cardullo and Rob Kitchin. Being a 'citizen' in the smart city: Up and down the scaffold of smart citizen participation. 2017.

[16] Marijn Janssen, Yannis Charalabidis, and Anneke Zuiderwijk. Benefits, Adoption Barriers and Myths of Open Data and Open Government. Information Systems Management, 29(4):258-268, 2012.

[17] Maarja Toots, Keegan Mcbride, Tarmo Kalvet, and Robert Krimmer. Open Data as Enabler of Public Service Co-creation : Exploring the Drivers and Barriers. In International Conference for E-Democracy and Open Government, pages 102-112, Krems, Austria, 2017. IEEE.

[18] Keegan D; Mcbride, Gerli; Aavik, Tarmo; Kalvet, and Robert Krimmer. CoCreating an Open Government Data Driven Public Service: The Case of Chicago's Food Inspection Forecasting Model. In 51st Hawaii International Conference on System Sciences (HICSS), pages 2453-2462. IEEE, 2018.

[19] Maarja Toots, Keegan McBride, Tarmo Kalvet, Robert Krimmer, Efthimios Tambouris, Eleni Panopoulou, Evangelos Kalampokis, and Konstantinos Tarabanis. A Framework for Data-Driven Public Service Co-Production. In International Conference on Electronic Government, pages 264-275, St.Petersburg, 2017. Springer. 